\title{
As feiras de rua em contextos metropolitanos: Porto e Barcelona
}

\author{
Márcio Ferreira (a), Catarina Maia (b), Teresa Sá Marques (c) \\ (a) Faculdade de Letras da Universidade do Porto, marcioferreira16@hotmail.com \\ (b) Centro de Estudos de Geografia e Ordenamento do Território (CEGOT)/Faculdade de Letras da Universidade do Porto (FLUP), \\ catarina.maia2@gmail.com \\ (c) Centro de Estudos de Geografia e Ordenamento do Território (CEGOT)/Faculdade de Letras da Universidade do Porto (FLUP), \\ teresasamarques@gmail.com
}

\begin{abstract}
Resumo
As feiras, enquanto atividade comercial, têm desempenhado um importante papel na dinamização das cidades. Depois de quase terem desaparecido das cidades, nos últimos anos têm reforçado o seu papel na animação urbana e na atração turística. Mas o seu papel, durante a crise e no pós-crise, poderá ter-se alterado.

Esta pesquisa foca-se na cidade do Porto e em Barcelona. Partindo de um levantamento das feiras e das suas principais características sócio-funcionais, desenvolveu-se uma tipologia da oferta e das respetivas procuras para a cidade do Porto, atualmente encontra-se em desenvolvimento na cidade de Barcelona. O principal objetivo é demonstrar a relevância intraurbana destas atividades socioeconómicas na animação dos diferentes sectores destas duas cidades. Neste artigo ir-se-á apresentar os primeiros resultados desta investigação.
\end{abstract}

Palavras chave: Geografia, Feiras, Economia Alternativa, Porto, Barcelona

\section{INTRODUÇÃO}

Ao longo da década passada, grande parte dos países europeus, e nomeadamente Portugal e Espanha, entraram num contexto de crise económica e financeira. Em resposta à crise, os governos implementaram um conjunto de medidas de austeridade que tiveram fortes impactos na vida económica e financeira das sociedades, sobretudo dos grupos sociais mais desfavorecidos e vulneráveis. Simultaneamente, as políticas públicas impulsionaram uma nítida retração dos apoios e da proteção social (Moreira, 2016; Ribeiro, R., Frade, C., Coelho, L., \& Ferreira-Valente, A., 2015).

Face a este contexto, surgiram novas iniciativas económicas, verificou-se um aumento de alternativas para ultrapassar as dificuldades económicas existentes, tendo-se desenvolvido novas atividades ligadas a competências existentes. Surgiram novas formas de pensar, de estar e de agir numa conjuntura de crise, procurando novas soluções e alternativas para combater as necessidades. Desenvolveram-se economias normalmente denominadas alternativas.

As atividades económicas alternativas surgem sobretudo em contextos de crise económica e social, procurando ser uma opção ao atual sistema económico capitalista, pois representam uma tentativa para criar outras opções e soluções, através de planos e estratégias alternativas de desenvolvimento económico, sobretudo a nível comunitário e local.

Algumas das principais atividades que se relacionam com a economia alternativa são: economia de partilha, economia solidária, bancos de tempo, moedas alternativas, hortas comunitárias, mercados de troca, mercados de usados, fleamarkets, espaços de coworking, etc (Botsman \& Rogers, 2009; Schor, 2014; Gibson-Graham, 2006; Hernández, 2017).

Estas atividades são sobretudo suportadas por redes de colaboração entre indivíduos ou organizações, de carácter sobretudo informal, sustentadas na troca de informação e conhecimento, mas também de bens e serviços (Méndez, 2015). Podem ser consideradas como atividades inovadoras, onde há mobilização de diferentes agentes na procura de respostas para problemas concretos. Além de poderem criar inovação económica, criam sobretudo inovação social, na medida em que, com um maior ou menor grau de criatividade, desenvolvem capacidades e competências nos indivíduos ou comunidades (Ferreira, 2017). 
As economias alternativas são consideradas, por alguns autores, como motores essenciais de apoio à resiliência local e urbana. Como refere Thieme (2016) "em questões de resiliência oferecem uma metáfora apropriada para ganhar impulso para futuros econômicos alternativos, baseados em lógicas de solidariedade e reciprocidade" (Thieme, 2016: p.2). Ricardo Méndez refere que "é nas cidades onde as ações de resistência, juntamente com a construção de novas alternativas políticas e económicas, têm uma maior presença e contribuem hoje para delinear novos cenários do futuro que são possíveis pela ação coletiva de uma cidadania progressivamente organizada. É a partir desta dupla perspetiva que o significado dessas redes colaborativas, que propõem uma economia com valores para avançar na recuperação das áreas urbanas após a crise, que pode ser identificado com o conceito de resiliência" (Méndez, 2015: p.15).

Os mercados de troca, fleamarkets, feiras, mercados de levante e os mercados informais são bons exemplos de práticas de economia alternativa. É notório que as feiras, enquanto atividades comerciais que se desenvolveram ao longo dos séculos, têm desempenhado um importante papel na construção e dinamização das cidades.

De acordo com o levantamento efetuado por Ferreira (2017), com a crise de 2008 houve um aumento significativo da criação de novos mercados e feiras na cidade do Porto, que aparecem com novos formatos e conceitos, sobretudo orientados para o artesanato e para a venda de produtos em segunda mão. Atualmente, continuam a estar presentes e perspetiva-se um eventual reforço da sua importância na animação urbana e turística da cidade.

As feiras são espaços económicos alternativos e muitas vezes de animação cultural. São mais que "mercados de trocas", são eventos socioculturais orientados para públicos heterogéneos. Além disso, são espaços que reúnem pessoas, fomentam a sociabilidade urbana e dinamizam os tecidos urbanos envolventes e o comércio local.

\section{ENQUADRAMENTO METODOLÓGICO E OBJETIVOS}

Este artigo é o resultado de um ensaio metodológico que se encontra atualmente em desenvolvimento nas cidades do Porto e Barcelona. O principal objetivo é demonstrar a relevância destas atividades económicas na vida económica e social destas duas cidades, em especial durante a crise e no pós-crise. Apresentar-se-á ao longo do artigo os primeiros resultados obtidos. De referir ainda que se excluiu deste estudo todos os mercados municipais, pois não se enquadram nesta pesquisa ${ }^{1}$. Deste modo, esta investigação tem objetivos:

$\checkmark \quad$ Caraterizar a oferta de feiras e mercados de rua, e de que forma a crise e o pós-crise tiveram impacto nesta oferta;

$\checkmark \quad$ Conhecer as dinâmicas recentes, tanto do lado da oferta e da procura, das feiras nos diferentes sectores da cidade;

$\checkmark \quad$ Demonstrar a relevância destas atividades económicas na vida económica e social destas duas cidades, tanto durante a crise como no pós-crise.

De forma a cumprir estes objetivos adotou-se uma metodologia testada no Porto (Ferreira, 2017). Os dados referentes às feiras da cidade do Porto correspondem a um levantamento efetuando entre 2016 e 2017. Os dados da cidade de Barcelona foram recolhidos em fevereiro de 2018. Em termos metodológicos começou-se por fazer a identificação e inventariação de todas as feiras e mercados de rua existentes, bem como de alguns dados de caraterização geral (por exemplo: periodicidade, horário) com base nas fontes oficiais: Website da Câmara Municipal do Porto, InfoPorto, PortoLazer, Agenda Virtual, mercatsbcn, ajuntament.barcelona e guia.barcelona.cat. De seguida realizou-se a cartografia das feiras, tendo em vista a localização das mesmas, utilizando-se as ferramentas Google Earth e ArcGis.

$\mathrm{Na}$ cidade do Porto já foi realizado todo o levantamento funcional. Na cidade de Barcelona só aplicamos o levantamento a 4 feiras, de forma a testar o método (efetuado presencialmente). Nesse levantamento recolheram -se vários dados para a análise e caraterização das feiras, entre os quais: $n^{\circ}$ de stands/bancas, $n^{\circ}$ de vendedores, $\mathrm{n}^{\circ}$ de clientes, área aproximada da feira em $\mathrm{m}^{2}$, área aproximada das bancas em $\mathrm{m}^{2}$ e tipos de produtos comercializados. Os próximos passos desta investigação passam pela elaboração de um levantamento funcional a todas as

\footnotetext{
1 "A principal razão dessa exclusão passa pelo facto de considerar-se, baseado nesta analise, que os Mercados que são diários, fixos, de venda de produtos de consumo diário e que possuem lojas físicas e fixas, não se enquadram neste tema da Economia Alternativa, pois nesses mercados não existem certas caraterísticas que são necessárias para se considerar como sendo uma economia alternativa. Alguns exemplos: 1) os Mercados Municipais necessitam de ter infraestruturas adequadas ao comércio, entre as quais instalações sanitárias, rede de água pública, rede elétrica, entre outros requisitos que fazem deles atividades de comércio a retalho sedentário; 2) nem sempre, quem comercializa nos mercados municipais, são os próprios produtores, mas sim subcontratados ou apenas comerciantes retalhistas; 3) funcionam praticamente todo o dia, têm um horário mais alargado." (Ferreira, 2017)
} 
feiras da cidade de Barcelona, de modo a ser possível comparar os resultados obtidos com o levantamento realizado às feiras da cidade do Porto.

Em termos metodológicos esta investigação também compreende inquéritos e entrevistas semiestruturadas aos clientes e feirantes das feiras do Porto e de Barcelona, bem como aos seus organizadores, de modo a conhecer e compreender as suas dinâmicas e suas características, antes e no pós-crise. Na cidade do Porto, já foram realizadas um conjunto significativo de inquéritos e entrevistas. Nesta comunicação será apresentada a parte inicial desta investigação, ainda em curso.

\section{AS FEIRAS NAS CIDADES DO PORTO E BARCELONA}

De acordo com o levantamento efetuado na cidade do Porto, existem 34 feiras e mercados de rua, dos quais 28 realizam-se durante o ano inteiro, com diferentes periodicidades, características e localizações. As restantes 6 feiras correspondem às feiras que apesar de terem uma certa regularidade são mais espaçadas no tempo e/ou apresentam uma quebra na sua realização. Essas 6 feiras têm frequências diferentes: 2 delas são anuais e as outras 4 possuem um carácter sazonal, isto é, realizam-se entre março a setembro.

$\mathrm{Na}$ cidade de Barcelona existem atualmente 66 feiras e mercados de rua, das quais 41 realizam-se o ano inteiro $(62,1 \%)$ com diferentes periodicidades, funcionalidades e localizações. As restantes 25 feiras realizam-se também de forma regular, mas têm uma particularidade, encerram em determinados meses, quebrando assim um pouco a sua regularidade. Mais concretamente: 10 feiras encerram durante dois meses (julho e agosto), 8 encerram em agosto e as restantes 7 encerram por mais de 3 meses (sendo consideradas como sazonais, à exceção de uma que é anual).

Na figura 1 pode-se visualizar o mapa da localização das feiras na cidade do Porto, onde se percebe que existe uma grande centralidade na localização das feiras na cidade do Porto. Mais concretamente, 22 das 34 feiras localizam-se no centro histórico e na "Baixa" do Porto e as restantes 12 feiras distribuem-se de forma mais dispersa pelo resto da cidade.

As feiras foram classificadas atendendo a algumas caraterísticas: periodicidade da feira, tipo de localização (fixa, móvel ou ambos), tipo de espaço onde se realizam (ao ar livre, em espaços fechados ou em ambos) e sua nomenclatura (nome atribuído).

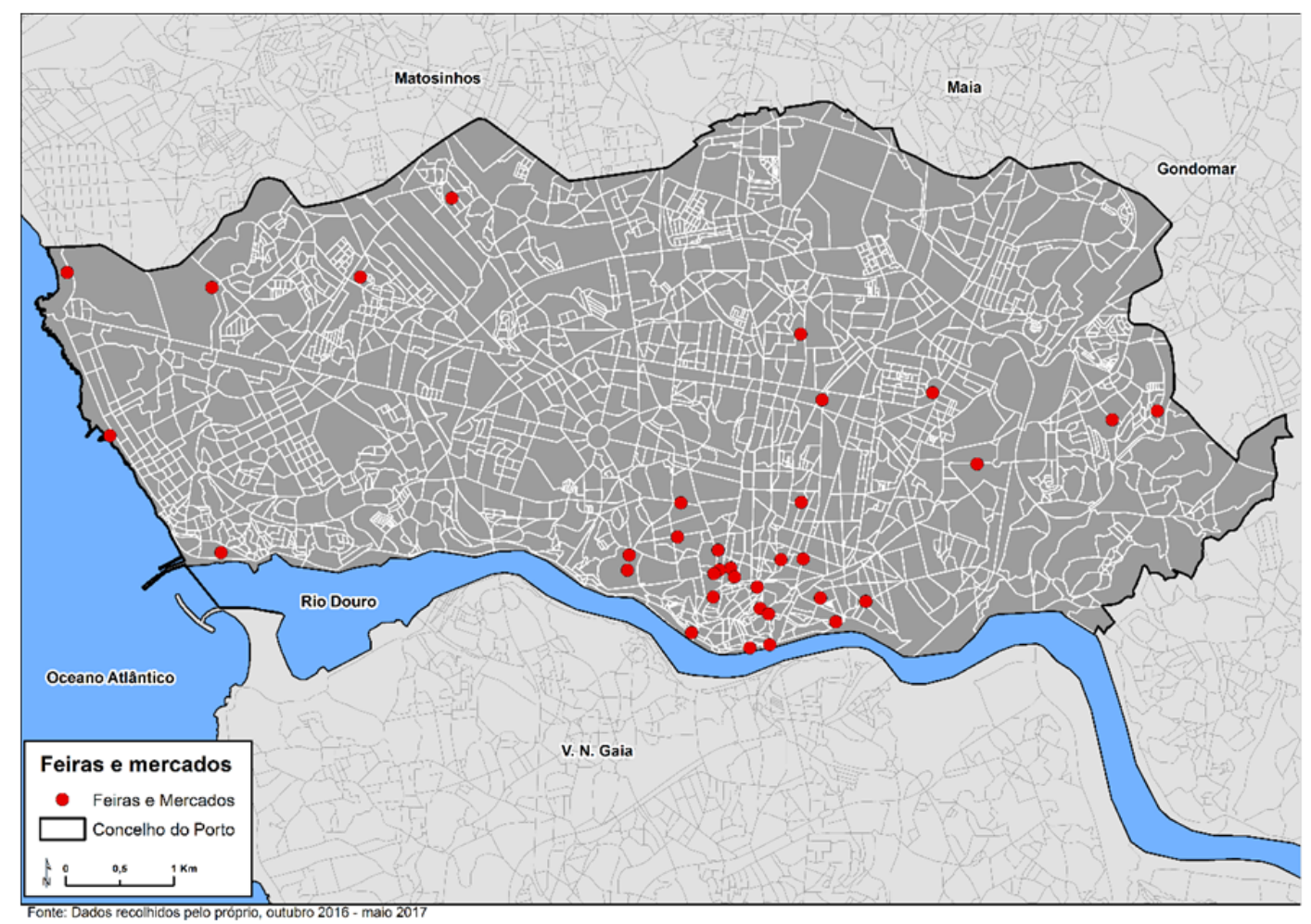

Figura 1 - Localização das feiras na cidade do Porto, 2017. Fonte: Elaboração própria 
Na figura 2 apresenta-se o mapa da localização das feiras na cidade de Barcelona, onde se constata que existe um padrão geográfico menos concentrado, quando comparado com o Porto. As feiras em Barcelona distribuem-se na malha urbana havendo assim um padrão locativo mais ou menos distribuído: 38 das 66 feiras localizam-se sobretudo no sul da cidade (57,6\%); um terço localiza-se junto ao centro histórico de Barcelona e as restantes 44 feiras dispersam-se na cidade. Assim, comparando com o Porto, as feiras da cidade de Barcelona apresentam um carácter mais disperso, com algumas aglomerações. Tal facto poderá relacionar-se com a diferença de tamanhos de ambas as cidades, onde o mais expectável será a existência de uma maior dispersão na cidade com maiores dimensões, como é o caso de Barcelona.

De seguida, efetuou-se uma classificação das feiras, através da informação disponível em alguns sítios: Website da Câmara Municipal do Porto, InfoPorto, PortoLazer, Agenda Virtual, mercatsbcn, ajuntament.barcelona e guia.barcelona.cat.

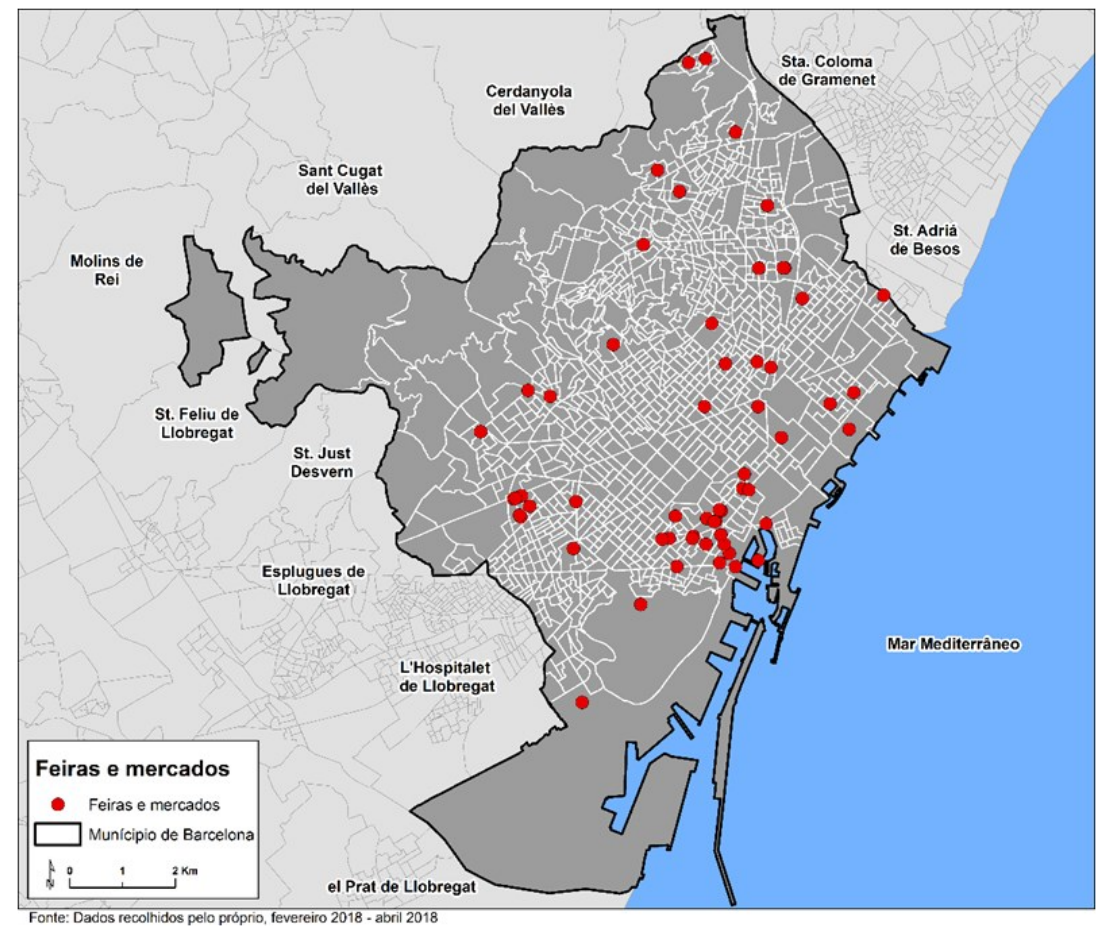

Figura 2 - Localização das feiras da cidade de Barcelona, 2018. Fonte: Elaboração própria

Em relação à periodicidade das feiras na cidade do Porto (figura 3), das 34 feiras existentes, 12 delas têm uma periodicidade semanal, 9 mensal e 8 diária (sobretudo mercados de levante que vendem produtos frescos). Das restantes 5 feiras, 3 apresentam uma periodicidade quinzenal e as outras 2 uma periodicidade anual.

Relativamente à cidade de Barcelona (figura 4), das 66 feiras existentes na cidade de Barcelona, 28 têm uma periodicidade semanal (42,4\%), 28 uma periodicidade mensal (42,4\%) e 6 realizam-se diariamente $(9,1 \%)$. Das restantes 4, 2 têm uma periodicidade quinzenal (3\%), 1 trimensal (1,5\%) e 1 feira realiza-se anualmente (1,5\%). Existe assim uma clara expressão das feiras semanais e mensais na cidade.

Relativamente ao tipo de localização das feiras, na cidade do Porto dominam as feiras que têm uma localização fixa (31 feiras), realizando-se sempre na mesma localização. As restantes 3 feiras têm um carácter móvel, isto é, vão alternando a sua localização geográfica ao longo das suas realizações. As feiras que apresentam essa característica são o Fleamarket, MarketPlace e o Urban Market - Portugal Lovers.

No que diz respeito à cidade de Barcelona, da amostra inventariada de 66 feiras, dominam as feiras que têm uma localização fixa (62 feiras), realizando-se sempre na mesma localização. As restantes 4 feiras têm um carácter móvel (Give me 5 market; Demanoenmano: el mercadillo social; Lost \& Found Market; Fira Tradicional de Productes Naturals de la Plaça Sagrada Família), isto é, vão alternando a sua localização ao longo das suas realizações.

Em relação ao tipo de espaço onde as feiras e mercados se realizam, pode-se identificar 2 tipos: as feiras ao ar livre, em praças, avenidas, jardins, entre outros; ou as feiras que são realizadas em espaços fechados, em pavilhões, 
galerias ou em armazéns. Conclui-se que a maioria das feiras na cidade do Porto se realizam em espaços ao ar livre, mais concretamente 24 feiras (figura 4). As restantes 10 feiras, 6 delas realizam-se em espaços fechados e as outras 4 feiras possuem um duplo carácter, isto é, tanto se realizam ao ar livre como em espaços fechados.

$\mathrm{Na}$ figura 6 observa-se que a esmagadora maioria das feiras na cidade de Barcelona ocorrem também ao ar livre, mais concretamente 56 das 66 feiras (84,8\%). As restantes 10 feiras, 6 apresentam-se de ambas as formas e as outras 4 ocorrem em espaços interiores.

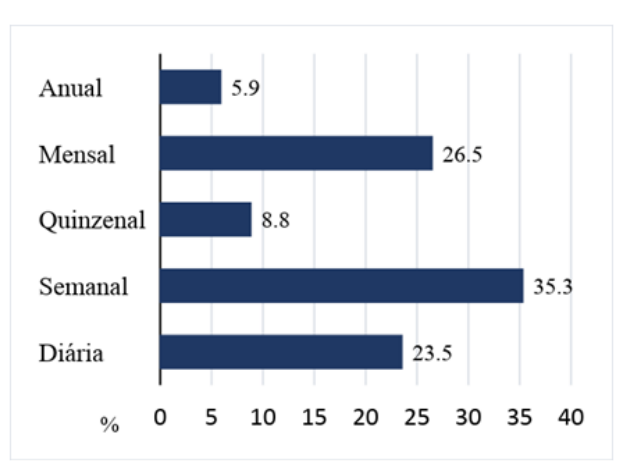

Figura 3 - Periodicidade das feiras no Porto, 2017. Fonte: Elaboração própria

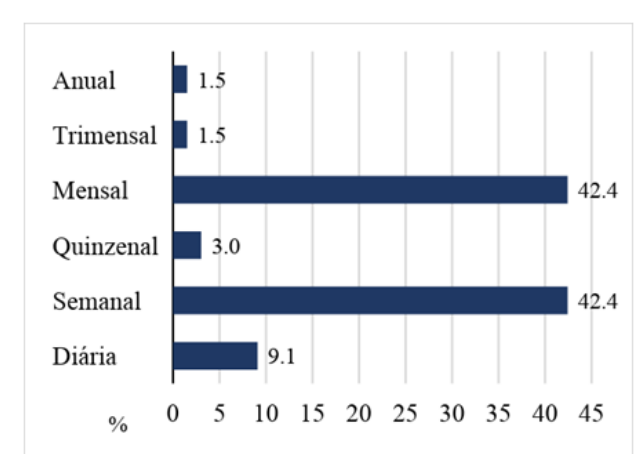

Figura 4 - Periodicidade das feiras em Barcelona, 2018

No que concerne às nomenclaturas atribuídas às feiras na cidade do Porto, como se pode observar na figura 7, no universo das 34 feiras, 14 (41,2\%) são designadas por "Feira", e representam nomenclaturas mais antigas e tradicionais. As restantes dividem-se da seguinte forma: 7 feiras (20,6\%) são designadas "Mercados de Rua", 7 feiras $(20,6 \%)$ "Mercados de Levante" e os outros $6(17,6 \%)$ têm outras designações, nomeadamente estrangeirismos, como é o caso das seguintes feiras: MarketPlace-Casual Style, Urban Market - Portugal Lovers.

Em relação à cidade de Barcelona, como se pode observar na figura 8, as nomenclaturas que mais se destacam são a "Feira" com 25 ocorrências (37,9\%) e o "Mercado" com 23 entradas (34,8\%). As restantes 18 feiras dividem-se da seguinte forma: 13 (19,7\%) são sobretudo estrangeirismos ou outros nomes não habituais, por exemplo: On The Garage, El rastro de la virgen, Give me 5 market, entre outros. As restantes 5 feiras (7,6\%) têm como nomenclatura "Mostra" ou exposição.

Concluindo, com uma breve caracterização inicial conseguiu-se encontrar algumas semelhanças e diferenças: o perfil locativo das feiras da cidade do Porto é mais concentrado do que o perfil de Barcelona, pois esta cidade apresenta uma estrutura de localização mais distribuída com algumas pequenas aglomerações. Nas duas cidades, a maioria das feiras têm uma localização fixa e são normalmente realizadas ao ar livre. Em Barcelona existe uma grande percentagem de feiras que encerram um, dois ou três meses seguidos, algo que no Porto é raro ocorrer. Na periodicidade das feiras, na cidade do Porto predominam sobretudo as feiras semanais enquanto em Barcelona existe um maior equilíbrio (o número de feiras semanais é igual ao número de feiras mensais). Na cidade de Barcelona ocorrem com menor frequência as feiras diárias.

As tabelas 1 e 2 expõem o levantamento parcial efetuado na cidade de Barcelona e o levantamento funcional efetuado na cidade do Porto.

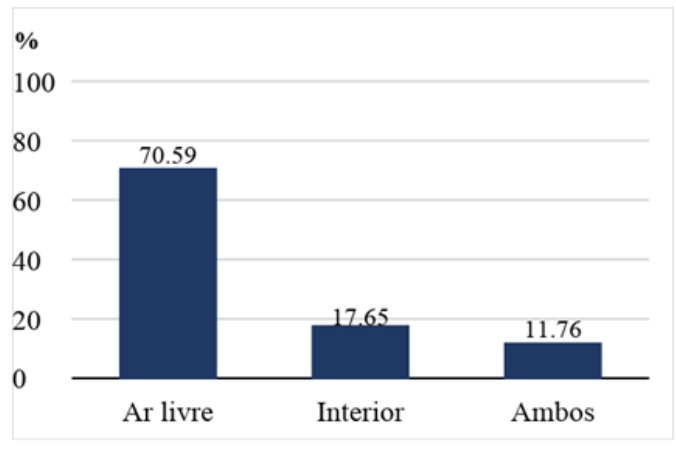

Figura 5 - Tipologia de espaço das feiras, Porto, 2017. Fonte: Elaboração própria.

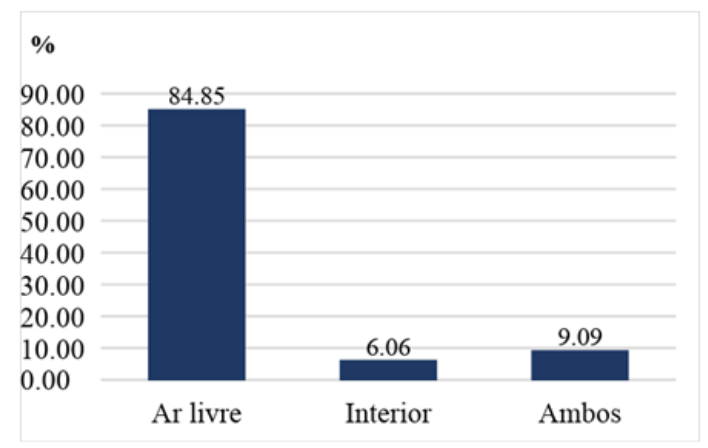

Figura 6 - Tipologia de espaço das feiras, Barcelona, 2018 


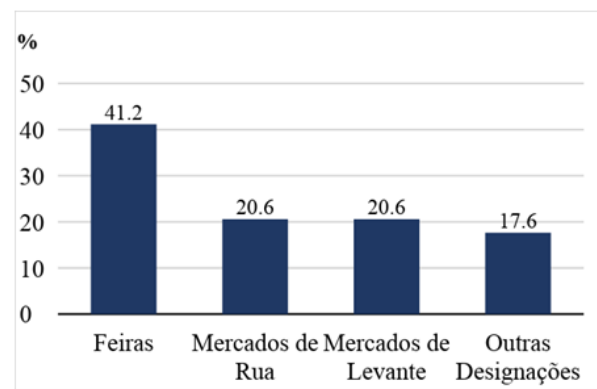

Figura 7 - Nomenclatura das feiras, Porto, 2017. Fonte: Elaboração própria.

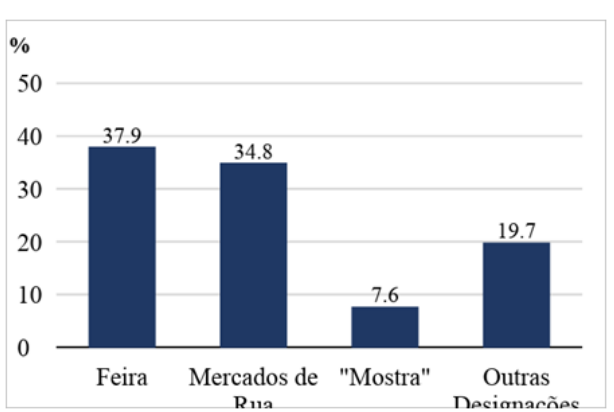

Figura 8 - Nomenclatura das feiras, Barcelona, 2018

Tabela 1 - Levantamento funcional, teste efetuado na cidade de Barcelona. Fonte: Márcio Ferreira (2018).

\begin{tabular}{|l|r|r|r|r|r}
\hline Nome & $\begin{array}{c}\text { No de } \\
\text { Bancas }\end{array}$ & \multicolumn{1}{|c|}{$\begin{array}{c}\text { No de } \\
\text { vendedores }\end{array}$} & $\begin{array}{c}\text { No de } \\
\text { clientes }\end{array}$ & $\begin{array}{c}\text { Área ocupada } \\
\text { aproximada (m2) }\end{array}$ & $\begin{array}{c}\text { Área aproximada } \\
\text { das bancas (m2) }\end{array}$ \\
\hline $\begin{array}{l}\text { Mercat Gòtic Antiguitats } \\
\text { *Plaça Nova }\end{array}$ & 27 & 30 & 120 & 650 & 3 \\
\hline $\begin{array}{l}\text { Fira Nova Artesania } \\
\text { *Rambles }\end{array}$ & 46 & 52 & 150 & 600 & 3 \\
\hline $\begin{array}{l}\text { Fira d'Artesans Moll de } \\
\text { Dipòsit }\end{array}$ & 20 & 22 & 100 & 500 & 3 \\
\hline $\begin{array}{l}\text { Mercat d'Antiguitats Port } \\
\text { Antic }\end{array}$ & 19 & 26 & 50 & 400 & 4
\end{tabular}

Tabela 2 - Levantamento funcional das feiras da cidade do Porto.

Fonte: Márcio Ferreira (2017).

\begin{tabular}{|c|c|c|c|c|c|}
\hline Nome & $\begin{array}{l}\mathrm{N}^{\bullet} \text { de } \\
\text { bancas }\end{array}$ & $\begin{array}{l}\mathbf{N}^{\circ} \text { de } \\
\text { vendedores }\end{array}$ & $\mathrm{N}^{\circ}$ de clientes & $\begin{array}{l}\text { Área ocupada } \\
\text { aproximada }\left(\mathrm{m}^{2}\right)\end{array}$ & $\begin{array}{l}\text { Área } \\
\text { aproximada } \\
\text { das bancas } \\
\left(\mathrm{m}^{2}\right)\end{array}$ \\
\hline Feira da Vandoma & 419 & 635 & $1000+$ & $5440^{*}$ & 6 \\
\hline Fleamarket Porto & 207 & 309 & 500 & 4000 & 5 \\
\hline Feira do Cerco & 174 & 272 & 850 & 9000 & 5 \\
\hline MarketPlace & 87 & 116 & 200 & 3000 & 3 \\
\hline $\begin{array}{l}\text { Feira de Artesanato Urbano } \\
\text { "Familia desce à rua" }\end{array}$ & 81 & 96 & 150 & 800 & 3 \\
\hline $\begin{array}{l}\text { Feira Antiguidades e } \\
\text { Velharias }\end{array}$ & 63 & 82 & 180 & 2500 & 3 \\
\hline Mercado da Alegria & 53 & 66 & 80 & 1600 & 3 \\
\hline Mercadinho dos Clérigos & 44 & 40 & 142 & 350 & 2 \\
\hline $\begin{array}{l}\text { Feira de Numismática, } \\
\text { Filatelia e Coleccionismo }\end{array}$ & 40 & 44 & 55 & 841 & 5 \\
\hline $\begin{array}{l}\text { Mercado de Artesanato do } \\
\text { Porto }\end{array}$ & 37 & 46 & 46 & 600 & 3 \\
\hline Feira dos Passarinhos & 36 & 60 & 250 & 600 & 2 \\
\hline Urban Market & 26 & 32 & 20 & 320 & 3 \\
\hline Mercado Porto Belo & 25 & 29 & 40 & 900 & 3 \\
\hline Pink Market & 22 & 34 & 25 & 140 & 3 \\
\hline Feira de Velharias e Vintage & 21 & 21 & 25 & 2300 & 6 \\
\hline Artesanato de Santa Catarina & 14 & 18 & 100 & 4500 & 3 \\
\hline Mercado Caótico & 14 & 16 & 10 & 150 & 3 \\
\hline $\begin{array}{l}\text { Feira de Produtos de } \\
\text { Agricultura Biológica }\end{array}$ & 10 & 20 & 30 & 300 & 7 \\
\hline$O$ berdinho & 10 & 10 & 15 & 100 & 2 \\
\hline Livros na Reitoria & 10 & 10 & 12 & 200 & 3 \\
\hline Mercado de S. Sebastião & 8 & 10 & 9 & 500 & 4 \\
\hline Feira de artes e culturas & 8 & 10 & 10 & 80 & 2 \\
\hline Mercado das Campinas & 6 & 6 & 5 & 80 & 4 \\
\hline Mercado da Ribeira & 6 & 9 & 5 & 400 & 4 \\
\hline Mercado do Cerco do Porto & 5 & 5 & 4 & 50 & 3 \\
\hline Mercado do Viso & 4 & 4 & 4 & 120 & 3 \\
\hline Mercado do Covelo & 2 & 2 & 2 & 100 & 3 \\
\hline Mercado Praça da Alegria & 2 & 2 & 3 & 80 & 4 \\
\hline
\end{tabular}




\section{DA CRISE AO PÓS-CRISE}

Em termos qualitativos, as entrevistas e os inquéritos estão em curso, tendo avançado sobretudo na cidade do Porto. Em termos sintéticos podem-se desde já referir algumas constatações para a cidade do Porto, que serão posteriormente avaliadas também em Barcelona.

A dinâmica das feiras foi impulsionada pela crise que se instaurou em meados de 2008. As feiras tiveram um papel muito importante na sobrevivência de algumas famílias ao longo da crise, constituindo um rendimento fundamental ou complementar essencial. Com a dinâmica turística da cidade, registada nos últimos anos, algumas feiras registaram um aumentou muito considerável da procura. Atualmente encontram-se numa fase de grande ascensão, havendo cada vez mais e desenvolvendo diferentes conceitos. Portanto, surgiram como resposta à crise, e têm vindo a afirmar-se e a diferenciar-se no período de pós-crise.

$\mathrm{Na}$ cidade do Porto as feiras refletem a segmentação social da cidade, que é visível nas características sociais dos feirantes, mas também nos produtos que são vendidos. A crise e o pós-crise também se manifestam de diferentes formas nos vários sectores da cidade.

No sector oriental da cidade, dominam as feiras mais tradicionais, com produtos convencionais de fraca qualidade e indiferenciados. O perfil de oferta e de procura não variou significativamente na crise e no pós-crise. Uma oferta pouco qualificada e uma procura com fraca capacidade económica e pouco exigente. Em termos comparativos, o sector central e ocidental da cidade, durante a crise, atraiu feiras mais diferenciadoras, com uma oferta mais significativa de produtos criados pelos próprios produtores/vendedores. Aqui a procura evidencia uma maior capacidade económica, com os indivíduos e as famílias a procurem as feiras enquanto espaços de sociabilidade urbana, pretendendo adquirir produtos aparentemente únicos, que incorporam criatividade e conhecimento simbólico. O pós-crise associou-se à atratividade turística da cidade e estas feiras ganharam novos segmentados de procura e ambiências multiculturais.

\section{BIBLIOGRAFIA}

BOTSMAN, R., \& ROGERS, R. (2009). What's Mine Is Yours: Bookman.

FERREIRA, M. (2017). Economia Alternativa: Feiras e AirBnB na cidade do Porto. Dissertação de Mestrado, Faculdade de Letras da Universidade do Porto.

GIBSON-GRAHAM, J. K. (2006). A Postcapitalist Politics: University of Minnesota Press.

HERNÁNDEZ, J. L. S. (2017). Las prácticas económicas alternativas en perspectiva geográfica

MÉNDEZ, R. (2015). Redes de colaboración y economía alternativa para la resiliencia urbana: una agenda de investigación. Biblio3W, XX.

MOREIRA, I. (2016). O impacto da crise económica, financeira e social no acesso aos cuidados de saúde em Portugal. Universidade de Coimbra.

RIBEIRO, R., FRADE, C., COELHO, L., \& FERREIRA-VALENTE, A. (2015). Crise Económica em Portugal: Alterações nas Práticas Quotidianas e nas Relações Familiares. Paper presented at the $1^{\circ}$ Congresso da Associação Internacional das Ciências Sociais e Humanas em Língua Portuguesa Lisboa.

SCHOR, J. (2014). Debating the Sharing Economy. Great Transition Initiative.

THIEME, T. (2016). A Reflection on Resilient Urban Economies. 